\title{
Communication
}

\section{Sensitivity Improvement of Phi-OTDR by Fiber Cable Coils}

\author{
Konstantin V. Stepanov ${ }^{1, *}$, Andrey A. Zhirnov ${ }^{1,2}{ }^{\circledR}$, Kirill I. Koshelev ${ }^{1}$, Anton O. Chernutsky ${ }^{1}{ }^{\oplus}$, \\ Roman I. Khan ${ }^{1}$ and Alexey B. Pnev ${ }^{1,2}$ \\ 1 Bauman Moscow State Technical University, 2-nd Baumanskaya 5-1, 105005 Moscow, Russia; \\ a.zh@bmstu.ru (A.A.Z.); koshelev-k@yandex.ru (K.I.K.); chernutsky.a@bmstu.ru (A.O.C.); \\ khan.roman.igorevich@gmail.com (R.I.K.); pniov@bmstu.ru (A.B.P.) \\ 2 Kotelnikov Institute of Radioengineering and Electronics of RAS, Mokhovaya 11-7, 125009 Moscow, Russia \\ * Correspondence: stkv@bmstu.ru
}

check for

updates

Citation: Stepanov, K.V.; Zhirnov,

A.A.; Koshelev, K.I.; Chernutsky,

A.O.; Khan, R.I.; Pnev, A.B. Sensitivity Improvement of Phi-OTDR by Fiber Cable Coils. Sensors 2021, 21, 7077. https://doi.org/10.3390/s21217077

Academic Editor: José

Manuel Baptista

Received: 24 September 2021

Accepted: 24 October 2021

Published: 26 October 2021

Publisher's Note: MDPI stays neutral with regard to jurisdictional claims in published maps and institutional affiliations.

Copyright: (c) 2021 by the authors. Licensee MDPI, Basel, Switzerland. This article is an open access article distributed under the terms and conditions of the Creative Commons Attribution (CC BY) license (https:// creativecommons.org/licenses/by/ $4.0 /)$.

\begin{abstract}
We present a theoretical and experimental study in which we increased the sensitivity of a phase-sensitive optical time-domain reflectometer (phi-OTDR). This was achieved by constructing coils in the sensor cable, which increased the total amplitude of the impact on the fiber. We demonstrate this theoretically using the example of a phase-sensitive reflectometer model and practically in testing grounds with a buried nearby conventional sensor and a sensor with coils. The sensitivity increased 2.2 times. We detected $95 \%$ of events when using coils, versus $20 \%$ when using a straight cable. The suggested method does not require any modifications to the device.
\end{abstract}

Keywords: fiber optic sensor; distributed fiber optic sensor; phi-OTDR; sensitivity improvement

\section{Introduction}

Distributed fiber-optic systems (FOSs) are used in a large number of areas for recording acoustic impacts: in seismometry, including for oil wells [1-7]; for monitoring activity near long objects, such as perimeters and pipelines [8-10]; and for monitoring railway tracks and transport [11,12] as well as structures, including engines, buildings, and composite airplanes.

Scientists at the University of Texas under the leadership of GF Taylor introduced FOSs based on phase-sensitive reflectometry in the early 1990s [13-15]. Over the past years, many studies have been carried out on these systems in various directions, including signal recognition $[9,16,17]$, increasing the range of the controlled area [8,18-20], and increasing the system's spatial resolution [21-23].

One important parameter of such FOSs is their acoustic sensitivity threshold, that is, the minimum acoustic or vibration impact that the system can register. Several methods have been proposed to increase the acoustic sensitivity of FOSs, such as the use of a special cable with improved acoustic sensitivity [24-28], several photoreceivers together with special data-processing algorithms [29,30], and a special optical fiber with weak fiber Bragg gratings (wFBGs) recorded in a fiber with a known periodicity [31-34]. One possibility for increasing the SNR was investigated by using two probe pulses simultaneously [35-38], including with a certain polarization configuration $[39,40]$.

In this work, we study another way to increase the acoustic sensitivity of a phasesensitive optical time-domain reflectometer (phi-OTDR). Its advantages include simplicity and lack of need to upgrade any devices. The effect is achieved by using fiber coils in the cable in certain places or with some periodicity. This method of increasing the acoustic sensitivity does not exclude other existing methods and can be used together with them.

\section{Theory}

A phi-OTDR is a device that can detect acoustic impacts on a cable based on Rayleigh backscatter analysis. The schematic of the device is shown in Figure 1. The radiation source 
is a frequency-stabilized narrow-linewidth laser, with a coherence length that is much greater than the pulse half-width ( $\left.\tau_{\text {pulse }} \sim 10 \ldots 500 \mathrm{~ns}\right)$. This causes backscattered radiation interference in each pulse position. The continuous radiation from the laser is amplified by an erbium-doped fiber amplifier (EDFA). After the acousto-optic modulator (AOM) modulates the radiation to probing pulses, it goes to the sensor fiber through the circulator in the forward path. The backscattered radiation passes in the opposite direction in the circulator. Then, it is amplified by the pre-EDFA. Its amplified spontaneous emission (ASE) is excluded after it passes the narrow optical filter. Then, radiation enters the photodiode (PD) and is digitized on the analog-to-digital converter (ADC) before processing on the personal computer (PC).

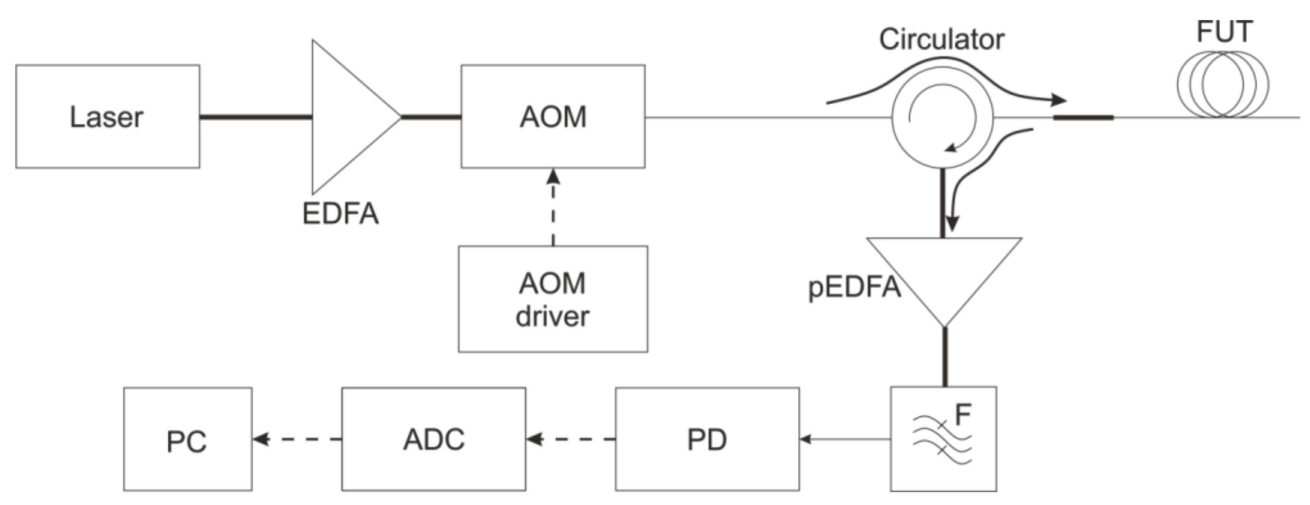

Figure 1. Phi-OTDR schematic.

Due to the long coherence length of the radiation source on the phi-OTDR's PD, the amplitudes of the backscattered waves are summed, taking into account their phases. For one probe pulse, the addition occurs over a section whose length is equivalent to the half-width of the pulse duration $\left(\Delta z=\frac{1}{2} \cdot \frac{c}{n} \cdot \tau_{\text {pulse }}\right)$, which is equal to the system's spatial resolution, where $c$ is the speed of light, and $n$ is the effective refractive index of fiber core. An acoustic wave from an external source decays with distance. If the wave reaches its maximum amplitude at each point of the fiber with a length of $\Delta z$, then attenuation due to the section length will not occur. The acoustic sensitivity will increase due to the fiber coils, since the amplitude of the impact over the entire interval of the spatial resolution does not decrease. This increases the impact's contribution on the resulting interference signal. The method's operating principles are demonstrated in Figure 2 for simulated data. Figure 2a shows how the intensity of fiber deformation depends on the cable's coordinates and the distance from the impact site. Figure $2 b$ shows a similar change in intensity when the cable is laid with a coil. Obviously, for the same cable length as in the first case, the greater level of impact is total. For example, compare the square under 1-7 $\mathrm{m}$ in graph $2 \mathrm{a}$ with that under 5-11 $\mathrm{m}$ in Figure 2b. Thus, the signal produced by the device also should increase in intensity.

Notably, in this case, it is necessary to match the fiber's length with the coordinates of the controlled object since the cable's physical length will also contain the length of the fiber spools.

If the reflecting centers on the fiber section for the two cases under consideration are displaced, then the attenuation of the amplitude along the length of the sensor will change. An example of the resulting picture of a simulation after filtering is shown in Figure 3. 
a)

b)

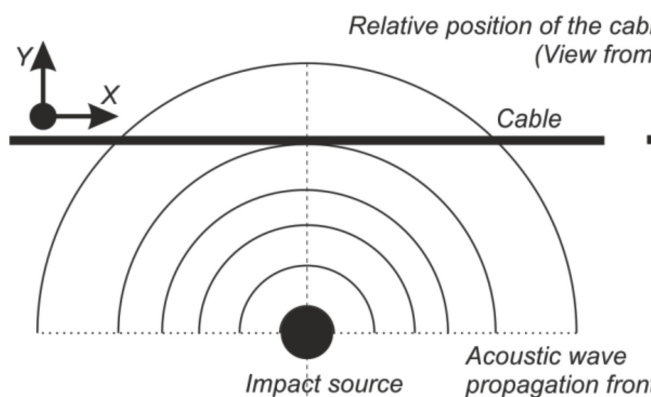

Fiber coil
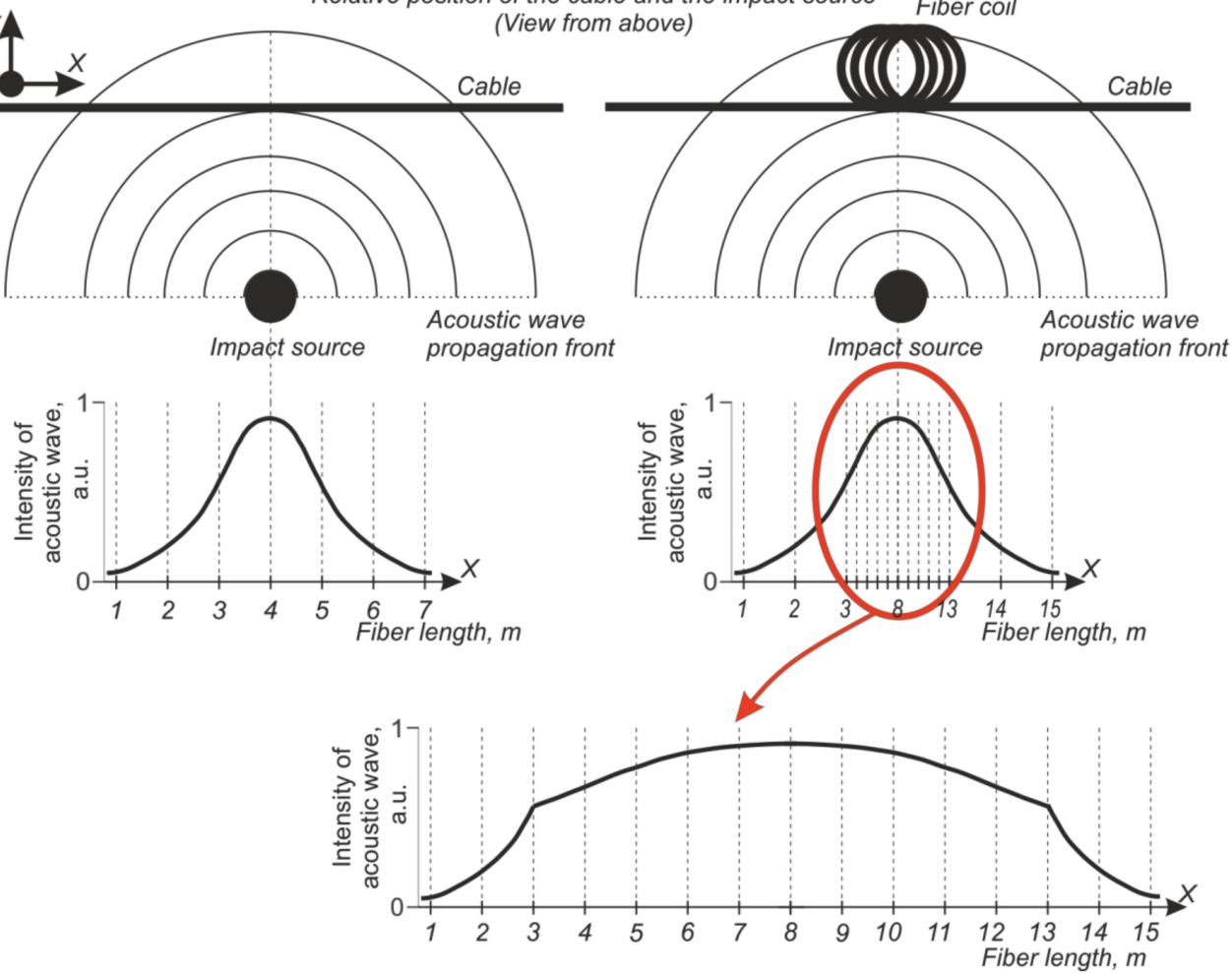

Figure 2. Diagram of the acoustic signal propagation for straight (a) and coil (b) configurations.
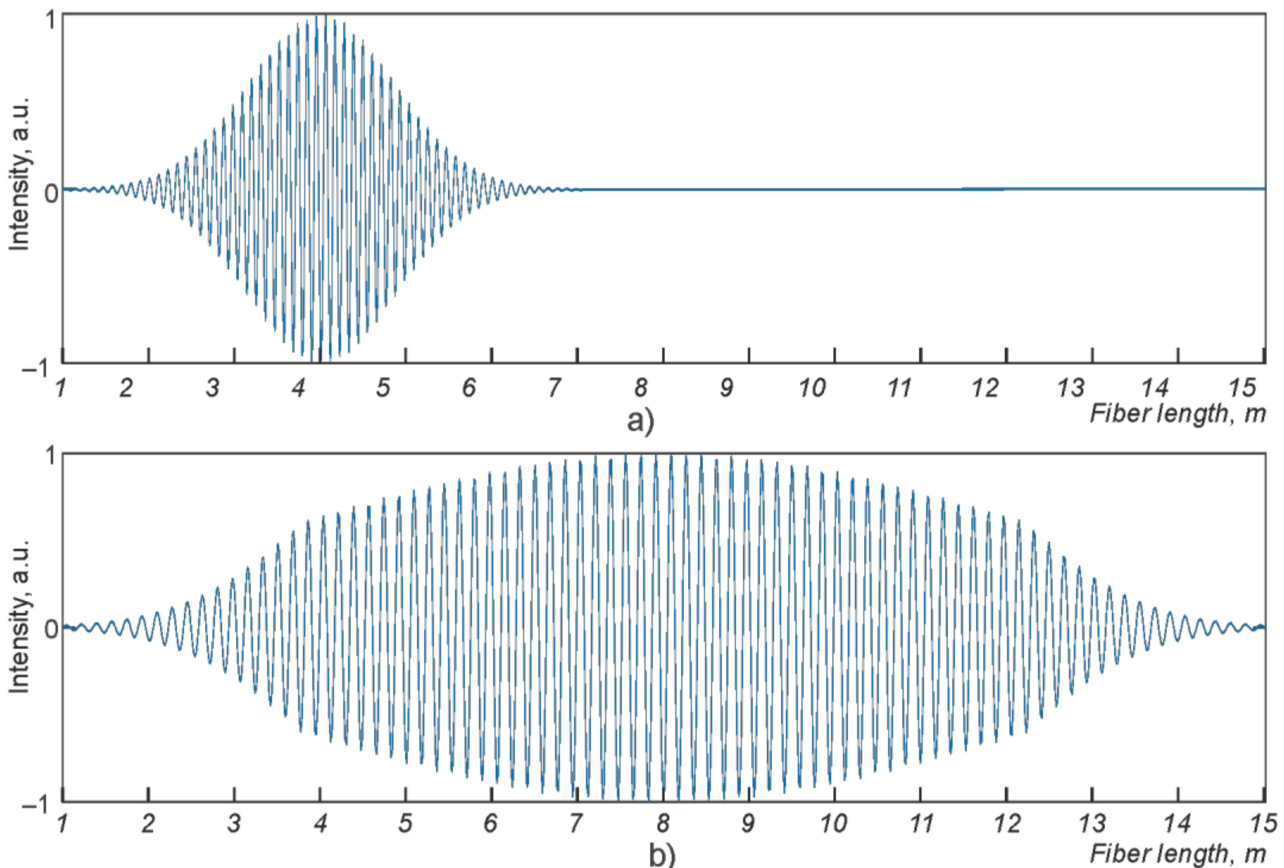

Figure 3. Plots of scattering center shift distributions along the cable for straight (a) and coil (b) configurations.

This change in the signal response will increase the impact's contribution in the data recorded by the receiver (Figure 4), which will increase the amplitude. Following the operating principles of a phi-OTDR, it is convenient to check this using the filtered signal, as shown in Figure 5. 


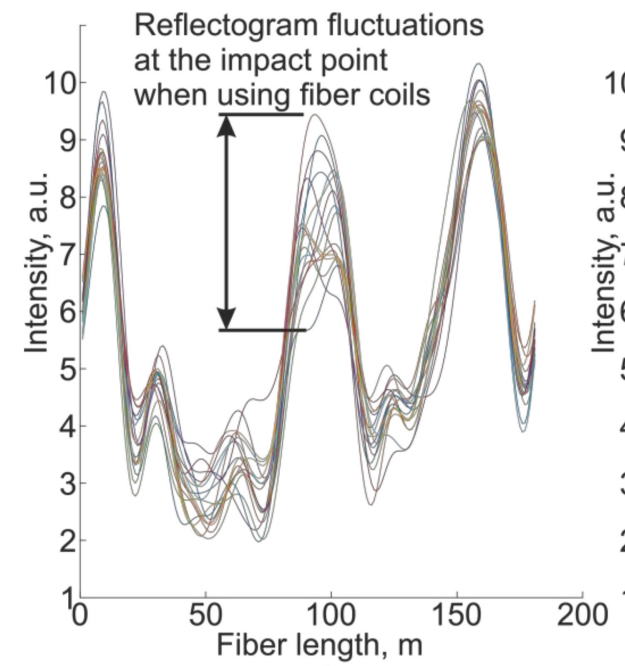

a)

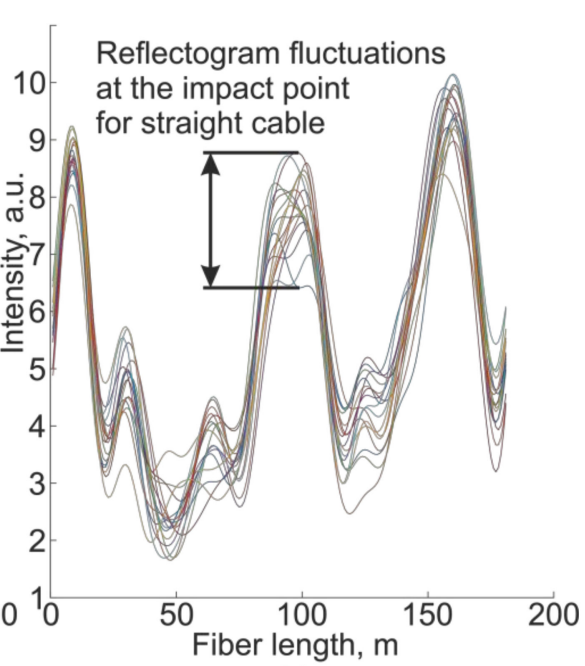

b)

Figure 4. Reflectogram fluctuations for the sensor with (a) and without (b) fiber coil.

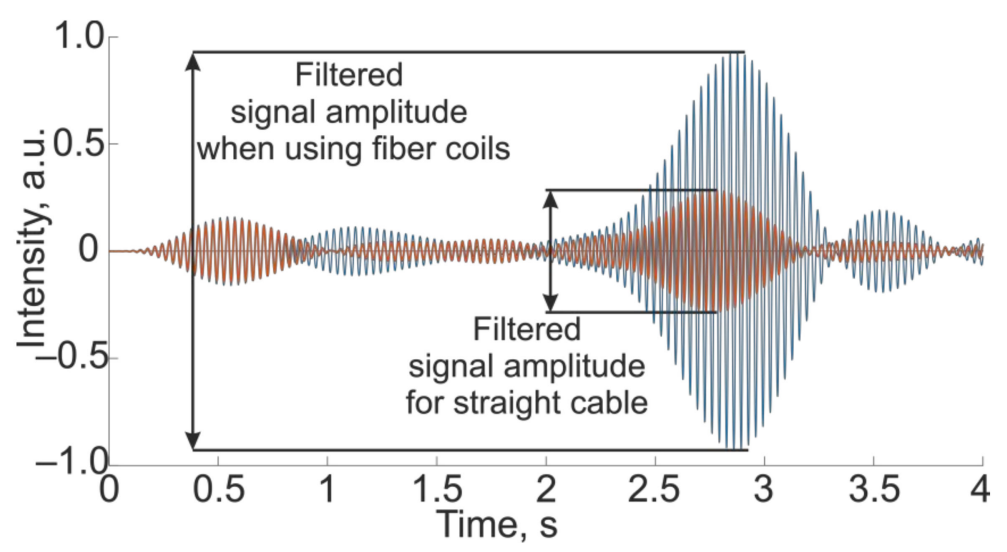

Figure 5. Filtered modeled signal for straight cable and fiber coils.

Fiber coils can be used for other applications than signal enhancement at a certain point. Some applications do not require using the full available length of the phi-OTDR sensor, e.g., perimeter monitoring of an object or a short pipeline that has a length less than $20 \mathrm{~km}$. The user only needs $20 \mathrm{~km}$ or less out of the usual $50 \mathrm{~km}$ length of a phi-OTDR. In such conditions, it is possible to create coils from cable length equal to the spatial resolution $\Delta z$ of the phi-OTDR with the same $\Delta z$ period between them in the buried trench. In such configurations, a fiber with length $L$ will be used for a sensor with length $L / 2$. Coils can be created on the entire sensor length or only in some special and important zones to enhance sensitivity.

\section{Modeling}

For theoretical analysis of the proposed method, a mathematical model was developed of the signal-formation process in a fiber-optic sensor system based on a phase-sensitive reflectometer with fiber coils. It is interpreted using the following considerations [41]. The amplitude for a point with the $x$ coordinate along the cable undergoes attenuation with a coefficient $\alpha$, and it also has the probability density of a Gaussian distribution, as determined by Formula (1):

$$
A(x)=A_{0} \cdot \exp (-2 x \alpha) \cdot p(a)
$$


where $p(a)=\frac{1}{\sigma \sqrt{2 \pi}} \exp \left\{-\frac{\left(a_{0}-a\right)^{2}}{2 \sigma^{2}}\right\}$ is the probability density of a Gaussian distribution, and $\sigma$ is the scale parameter.

The radiation source is not ideal and has instability over time. The array of values $v$ for the radiation frequency source within the interval of simulated time interval $\mathrm{T}$ at each moment is described by Equation (2):

$$
v=v_{0}+\left|F^{-1}\left\{\sqrt{S_{\nu} v_{\mathrm{p}}^{2} T}\right\}\right|
$$

where $v_{0}$ is the laser frequency at the initial moment, in $\mathrm{Hz} ; F^{-1}\{\}$ is the inverse Fourier transform; $S_{v}=\hat{S}_{v} \cdot|F\{\operatorname{rand}(1)\}|^{2} \frac{1}{v_{\mathrm{p}}^{2} T}$ is the laser frequency's instability, as determined by the envelope $\hat{S}_{v} ; v_{\mathrm{p}}$ is the the pulse repetition rate (in our case, $1 \mathrm{kHz}$ ); $T$ is the duration of simulated time, in s; and $F\{\}$ is the Fourier transform.

The radiation detected by the receiver has a phase that depends on the source wavelength $\lambda=c / v$ and the distance to point $x$ along the cable and is determined by Formula (3):

$$
\Theta(x)=\frac{4 \pi n(x+\Delta x)}{\lambda},
$$

where $n$ is the effective refractive index of the fiber core, and $\Delta x$ is the coordinate displacement due to external influence, in $\mu \mathrm{m}$.

In the simulation, a shift of the scattering centers was specified, similar to the shift of a fiber section wound around a piezoelectric cylinder. The simulation was carried out for various values of the maximum shear at the end of the piezoelectric $\Delta L_{\max }$ with the frequency $v_{a c}$. The impact is described by Equation (4):

$$
\Delta x(l, t)=\left\{\begin{array}{c}
\Delta L_{\text {max }} \cdot \frac{l}{l_{\text {max }}} \cdot \sin \left(2 \pi v_{a c} t\right) \\
0, \text { otherwise }
\end{array},\left\{\begin{array}{c}
0 \leq l \leq l_{\text {max }} \\
t \in t_{\text {impact }}
\end{array} .\right.\right.
$$

Thus, the complex amplitude from each point, taking the phase into account, is determined by Equation (5).

$$
E(x)=A(x) \cdot \exp (i \Theta(x))
$$

where $i$ is the imaginary unit.

For sensors based on phi-OTDR, the receiver detects the interference result of all backscattered waves at half-pulse width $\tau_{\text {pulse }} / 2$, which can be written according to Equation (6):

$$
E_{\text {sampling }}(x)=\int_{x}^{x+\frac{\tau_{\text {pulse }}}{2} \cdot \frac{c}{n}} E(\bar{x}) d \bar{x} .
$$

In addition to interference, the receiver has a transfer function, as defined by Equation (7).

$$
\operatorname{Mask}(v)=\exp \left(-\left[\frac{v}{v_{P D}}\right]^{2}\right)
$$

where $v_{P D}$ is the receiver's bandwidth.

By adding the receiver's transmittance function, expressed according to Formula (7), to the resulting intensity described by Formula (6), we obtain Expression (8), which determines the intensity recorded by the receiver for each point at coordinate $x$ along the cable. We obtain Formula (9) by writing out all of the components in this expression:

$$
I_{\text {Receiver }}(x)=\left|E_{\text {sampling }}(x)\right|^{2} \otimes F^{-1}\{\operatorname{Mask}(v)\},
$$


where $\otimes$ is the convolution operator.

$$
I_{\text {Receiver }}(x)=\left|\int_{x}^{x+\frac{\tau_{\text {pulse }}}{2} \cdot \frac{c}{n}} A_{0} \cdot \exp (-2 \bar{x} \alpha) \cdot p(a) \cdot \exp \left(i \frac{4 \pi n(\bar{x}+\Delta x)}{\lambda}\right) d \bar{x}\right|^{2} \otimes F^{-1}\left\{\exp \left(-\left[\frac{v}{v_{P D}}\right]^{2}\right)\right\} \text {. }
$$

The output data after the simulation were the SNR values for various input parameters, including the impact amplitudes. The SNR was calculated as follows.

After simulation, the original signal passed a narrow-band filter corresponding to the frequency of the impact. The algorithm used a 10th-order Butterworth bandpass filter with a $3 \mathrm{~dB}$ width of less than $5 \mathrm{~Hz}$ from the central frequency of exposure.

The standard deviation over time interval $\Delta t$ (for each sensor point) was considered without influence $\left(t \notin t_{\text {Imp }}\right)$. This value was equal to the $R M S_{\text {noImp }}$ parameter.

For the entire simulation time, the standard deviations (SDs) were found for time sections $\Delta t$ :

$$
\begin{gathered}
S N R_{S D}(i)=\frac{S D(i)}{S D_{\text {noImp }}} \\
S N R=\max \left(S N R_{S D}(i)\right)
\end{gathered}
$$

The data-processing stages from raw data to the final SNR values are shown in Figure 6.

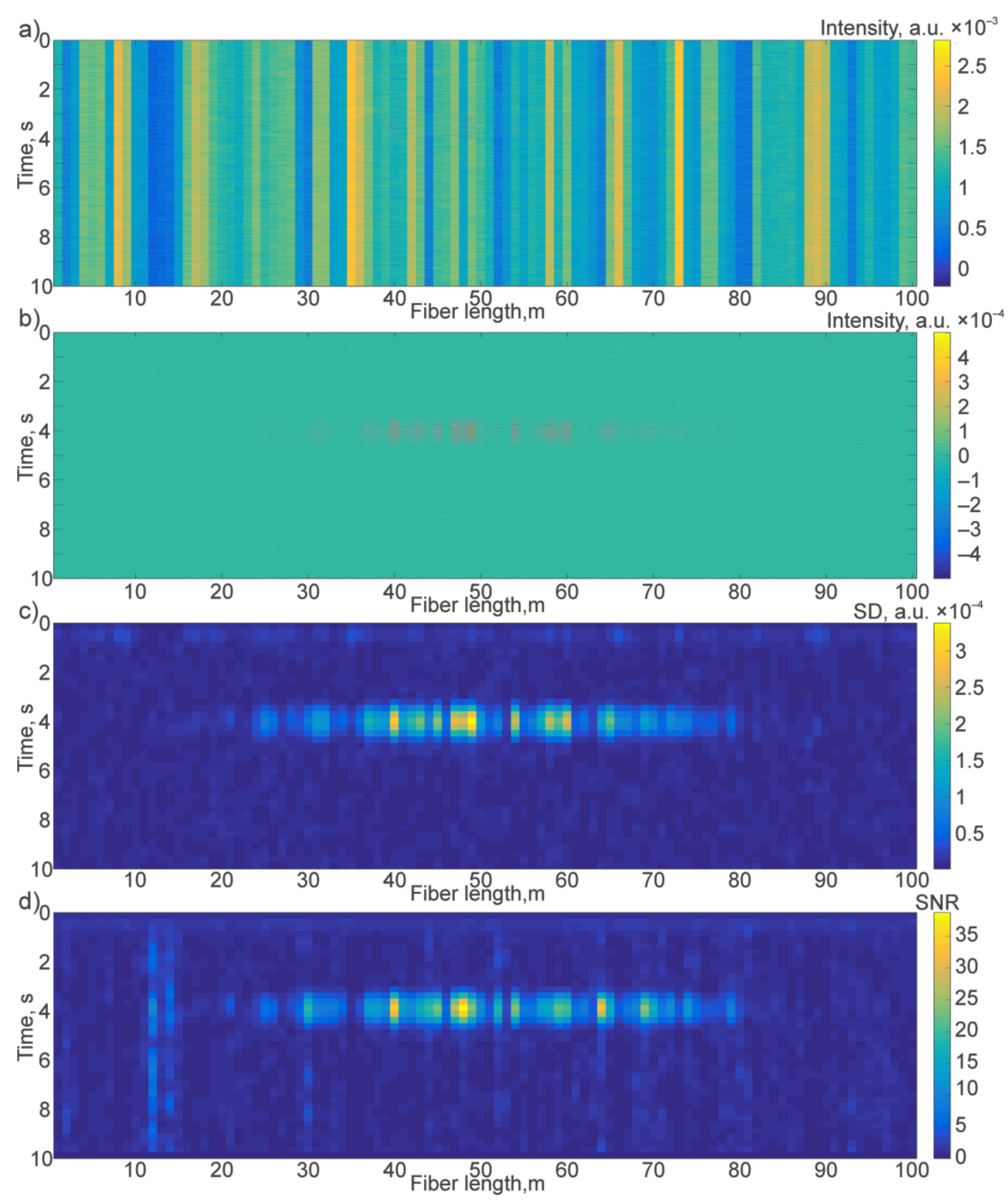

Figure 6. View of the data at different stages of the algorithm: (a) raw data with $1 \mathrm{kHz}$ discretization; (b) data after bandpass filtering; (c) filtered data of standard deviations in $500 \mathrm{~ms}$ windows with $250 \mathrm{~ms}$ steps; and (d) the final SNR with 250 ms steps. 
Due to the system behavior's random nature, the value of $S D_{n o I m p}$ can vary and have different values, even for areas where there is initially no impact. Because of this, the $S N R_{S D}$ can differ, and $S N R_{S D}>1$ in any region does not mean that there has been an impact. In further modeling, the condition chosen for stable recognition of an impact was when the largest value in the array $S N R_{S D}(i) \geq 5$.

For a more accurate assessment of the system, 1000 realizations were simulated for each amplitude of the impact. A simulation was carried out for two cases: a classic cable (attenuation of the impact immediately from the epicenter) and an increased length of optical fiber corresponding to the system's spatial resolution. In this case, an impact was simulated, and the classic cable showed amplitudes significantly lower than the threshold of $1 \mathrm{n} \varepsilon$. Distribution histograms of the obtained SNR values are shown in Figure 7.

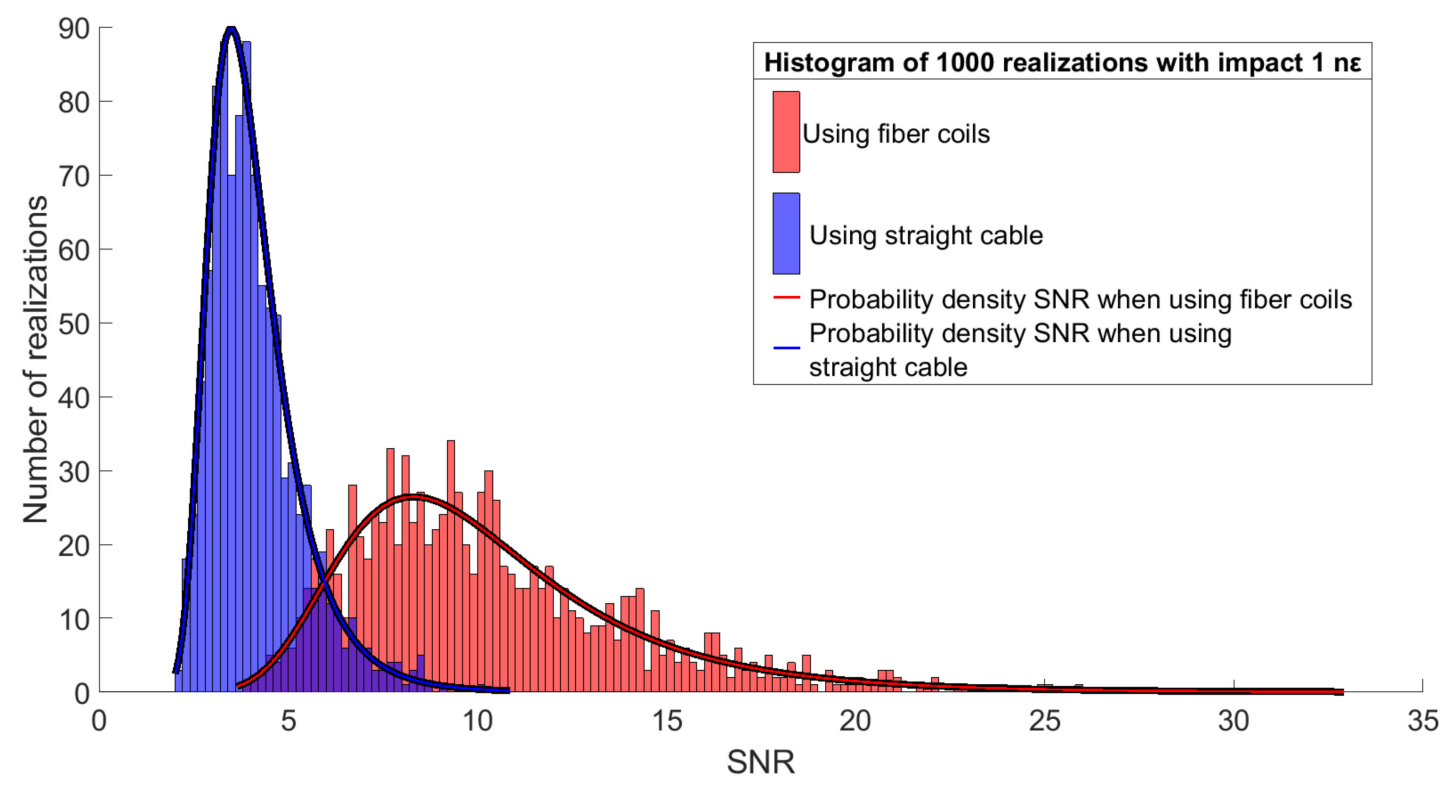

Figure 7. Histogram plots of SNR values for straight cable and fiber coil.

Table 1 compares the accuracy parameters between the straight cable and fiber coil methods.

Table 1. Accuracy parameters of different cables.

\begin{tabular}{ccc}
\hline Parameter & Straight Cable & Fiber Coil Method \\
\hline Distribution mode, SNR & 3.45 & 8.37 \\
Number of realizations with & 807 & 21 \\
SNR < 5 & $19.3 \%$ & $97.9 \%$ \\
Detection probability & & \\
\hline
\end{tabular}

The fiber coil method allowed the simulated impact amplitude parameters to increase the SNR by 2.5 times, which increased the detection probability to $95 \%$.

\section{Field Tests}

An experimental study of the proposed method based on fiber coils was carried out on the BMSTU test site. The optical fiber cable was buried in a $30 \mathrm{~cm}$ deep trench, which corresponds to the standard cable laying depth for DAS. In the experiment, we used one brand of optical cable in different laying configurations. The experimental setup is shown in Figure 8. 

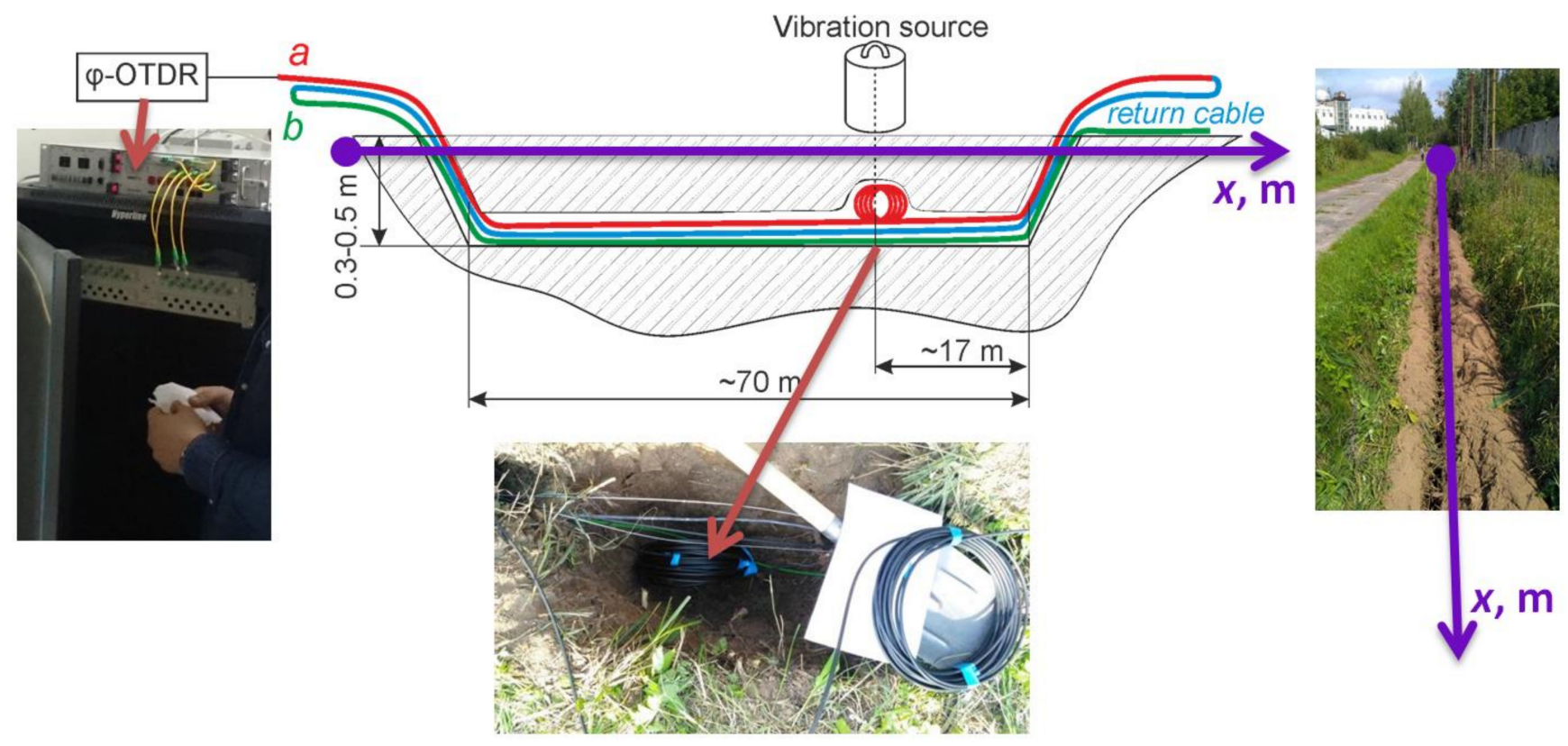

Figure 8. Diagram and photographs of the test setup.

The fiber cable configuration comprised a) a cable with a $10 \mathrm{~m}$ long fiber coil, corresponding to the system's spatial resolution of the system during the experiment, and b) a straight cable.

Table 2 shows the phi-OTDR parameters used for the experiments.

Table 2. The phi-OTDR parameters used for the experiments.

\begin{tabular}{cc}
\hline Parameter & Value \\
\hline ADC & $50 \mathrm{MHz}$ (the equivalent of $2 \mathrm{~m}$ spatial discretization) \\
Pulse duration & $100 \mathrm{~ns}$ \\
Spatial resolution & $10 \mathrm{~m}$ \\
Impact frequencies & $38 \mathrm{~Hz}, 55 \mathrm{~Hz}$, and $101 \mathrm{~Hz}$ \\
the cable & $0 \mathrm{~m}$ (over the cable), $2 \mathrm{~m}$, and $4 \mathrm{~m}$ \\
$\begin{array}{c}\text { Distance from the vibration source to } \\
\text { the }\end{array}$ & \\
\hline
\end{tabular}

The reasons for such parameter values were as follows. Frequencies of impacts in the vicinity of $38 \mathrm{~Hz}$ are common for recording events such as human passes and digging, since this range does not contain low-frequency noise from environment sources and laser wavelength deviation but is still just slightly attenuated in the soil. Frequencies in the region of $55 \mathrm{~Hz}$ were used for searching steps via fiber cable buried in rocky soil at a shallow depth. A frequency of $101 \mathrm{~Hz}$ was investigated as the cutoff frequency of sound propagation in the soil, above which strong attenuation begins. The distances to the vibration source were chosen according to requirements in monitoring systems for detecting steps using distributed acoustic sensors. The source of the vibration impacts had an uneven frequency response: at a frequency of $38 \mathrm{~Hz}$, the impact's amplitude was about 5 times higher than at an impact frequency of $101 \mathrm{~Hz}$.

Data obtained during the experiment are shown in Figure 9. Raw waterfalls in time duration from 6 to $16 \mathrm{~s}$ of the experiment represent the vibration start at the coil point $(1270 \mathrm{~m})$ and at the straight cable point $(1570 \mathrm{~m})$ in Figure 9a,b, respectively. Figure 9c,d show the signal spectra at marked points. For the point with coil, all impact frequencies and a few harmonics for $38 \mathrm{~Hz}$ are visible. For the straight cable only $38 \mathrm{~Hz}$ and $55 \mathrm{~Hz}$ peaks are observable. Figure $9 \mathrm{e}, \mathrm{f}$ show bandpass-filtered data for the marked points during the entire experiment. 


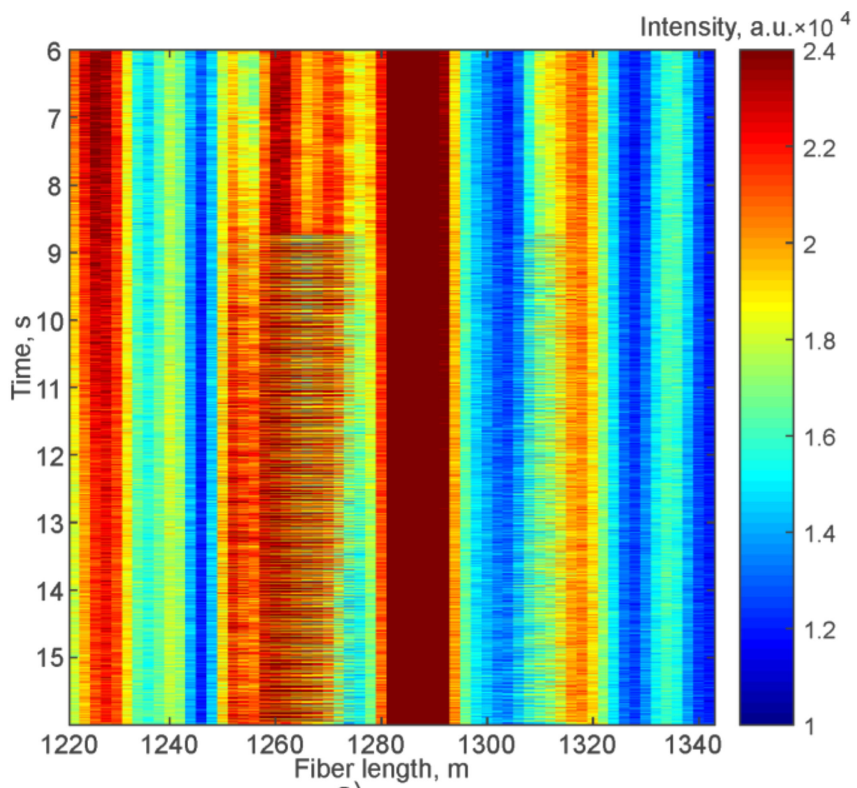

a)

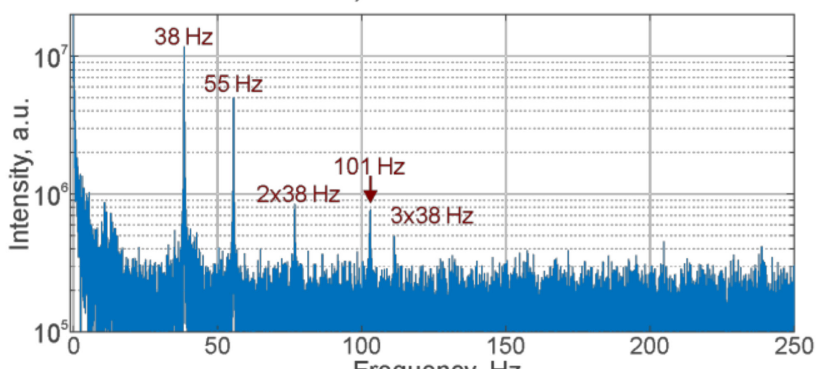

c)
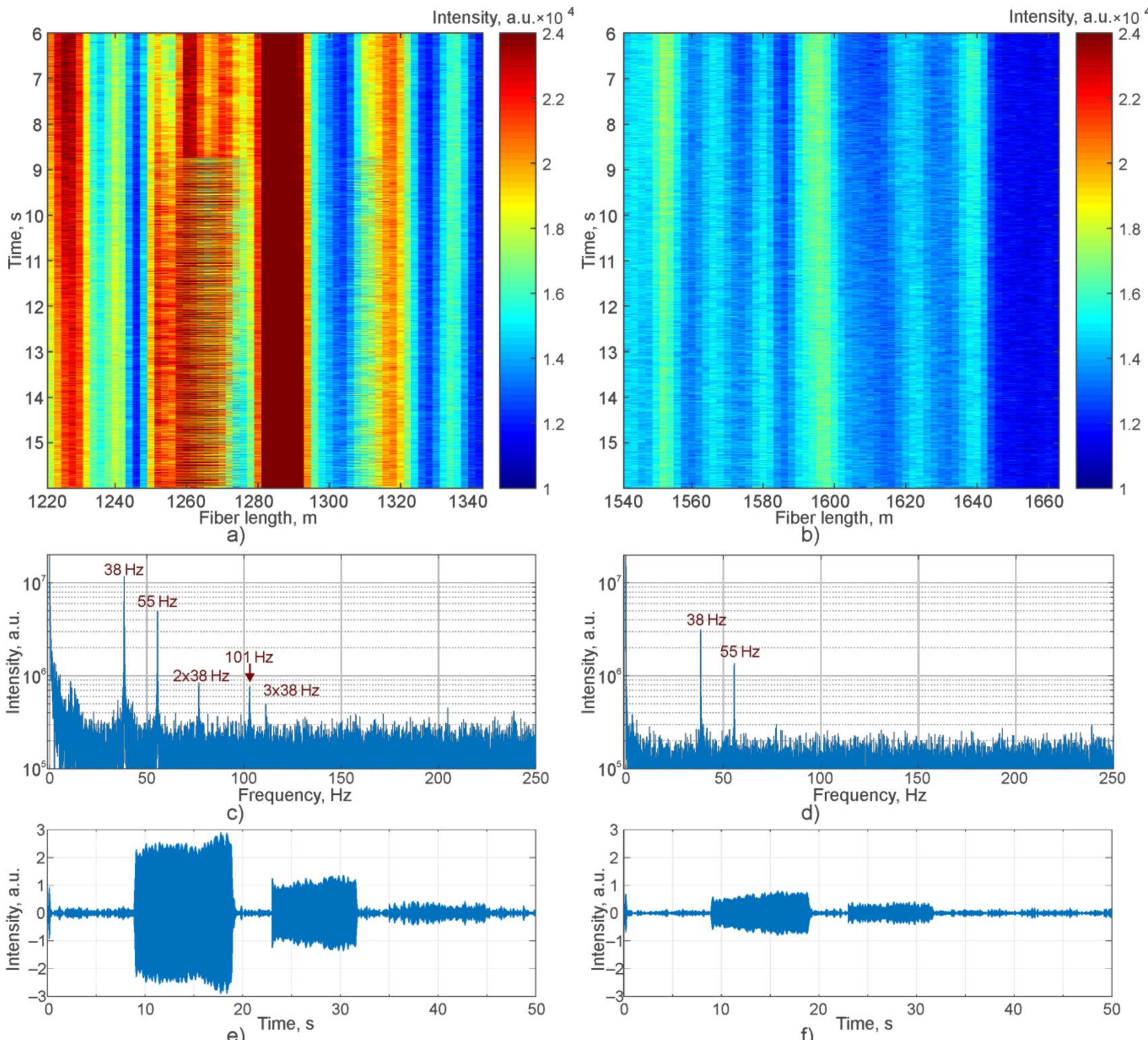

b)

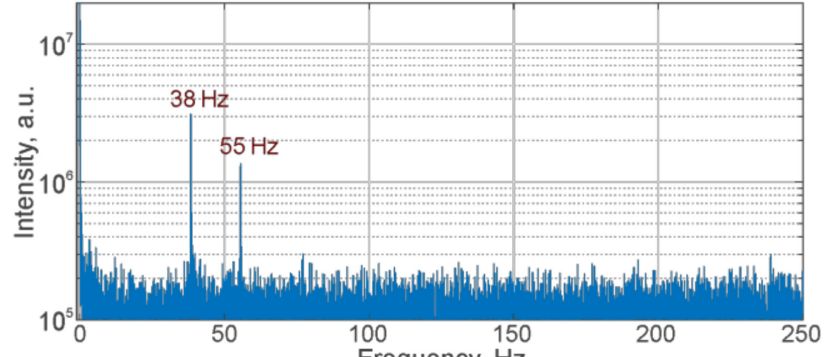

d)

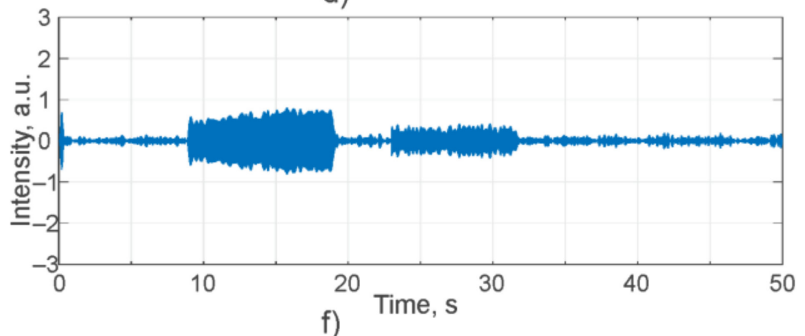

Figure 9. Experimental data: (a) raw data waterfall of vibration start for the coil point (1270 m); (b) raw data waterfall of vibration start for the straight cable point $(1570 \mathrm{~m})$; (c) signal spectrum for the $1270 \mathrm{~m}$ point; (d) signal spectrum for the $1570 \mathrm{~m}$ point; bandpass-filtered data during the entire experiment at the $1270 \mathrm{~m}(\mathbf{e})$ and $1570 \mathrm{~m}(\mathbf{f})$ points.

The obtained experimental data confirmed the rapid degradation of weak vibration impacts as the point of influence moves away from the cable [42]. The vibration influence at a $38 \mathrm{~Hz}$ frequency, which had a higher power (due to the source's uneven characteristics), together with a lower attenuation coefficient in the ground, also underwent attenuation with distance but was successfully recorded in all of the experimental configurations.

Table 3 and Figure 10 show the SNR values obtained for each experiment for cables a and $b$. 
Table 3. Experimental SNR values.

\begin{tabular}{|c|c|c|c|}
\hline & \multirow{3}{*}{$\begin{array}{c}\text { Straight Cable } \\
\text { Mean dimensionless SNR at } 38 \mathrm{~Hz} \\
(\text { Number of experiments with SNR > 5) }\end{array}$} & \multicolumn{2}{|c|}{ Fiber Coil } \\
\hline & & & Dimensionless \\
\hline & & & SNR increase \\
\hline $0 \mathrm{~m}$ (over the cable) & $15.75(10$ of 10$)$ & $39.37(10$ of 10$)$ & 2.50 \\
\hline $2 \mathrm{~m}$ from the cable & $8.64(7$ of 10$)$ & $27.09(10$ of 10$)$ & 3.13 \\
\hline $4 \mathrm{~m}$ from the cable & $8.09(9$ of 10$)$ & $18.8(10$ of 10$)$ & 2.25 \\
\hline \multicolumn{4}{|c|}{$\begin{array}{c}\text { Mean dimensionless SNR at } 55 \mathrm{~Hz} \\
\text { (Number of experiments with SNR > 5) }\end{array}$} \\
\hline $0 \mathrm{~m}$ (over the cable) & $15.27(10$ of 10$)$ & $33.03(10$ of 10$)$ & 2.16 \\
\hline $2 \mathrm{~m}$ from the cable & $4.66(5$ of 10$)$ & $13.18(10$ of 10$)$ & 2.83 \\
\hline $4 \mathrm{~m}$ from the cable & $3.98(1$ of 10$)$ & 4.88 (5 of 10$)$ & 1.23 \\
\hline \multicolumn{4}{|c|}{$\begin{array}{c}\text { Mean dimensionless SNR at } 101 \mathrm{~Hz} \\
\text { (Number of experiments with SNR > 5) }\end{array}$} \\
\hline $0 \mathrm{~m}$ (over the cable) & $7.66(7$ of 10$)$ & $9.96(9$ of 10$)$ & 1.30 \\
\hline $2 \mathrm{~m}$ from the cable & $1.82(0$ of 10$)$ & $4.14(3$ of 10$)$ & SNR $<5$ \\
\hline $4 \mathrm{~m}$ from the cable & $1.93(0$ of 10$)$ & $2.03(0$ of 10$)$ & $\mathrm{SNR}<5$ \\
\hline
\end{tabular}

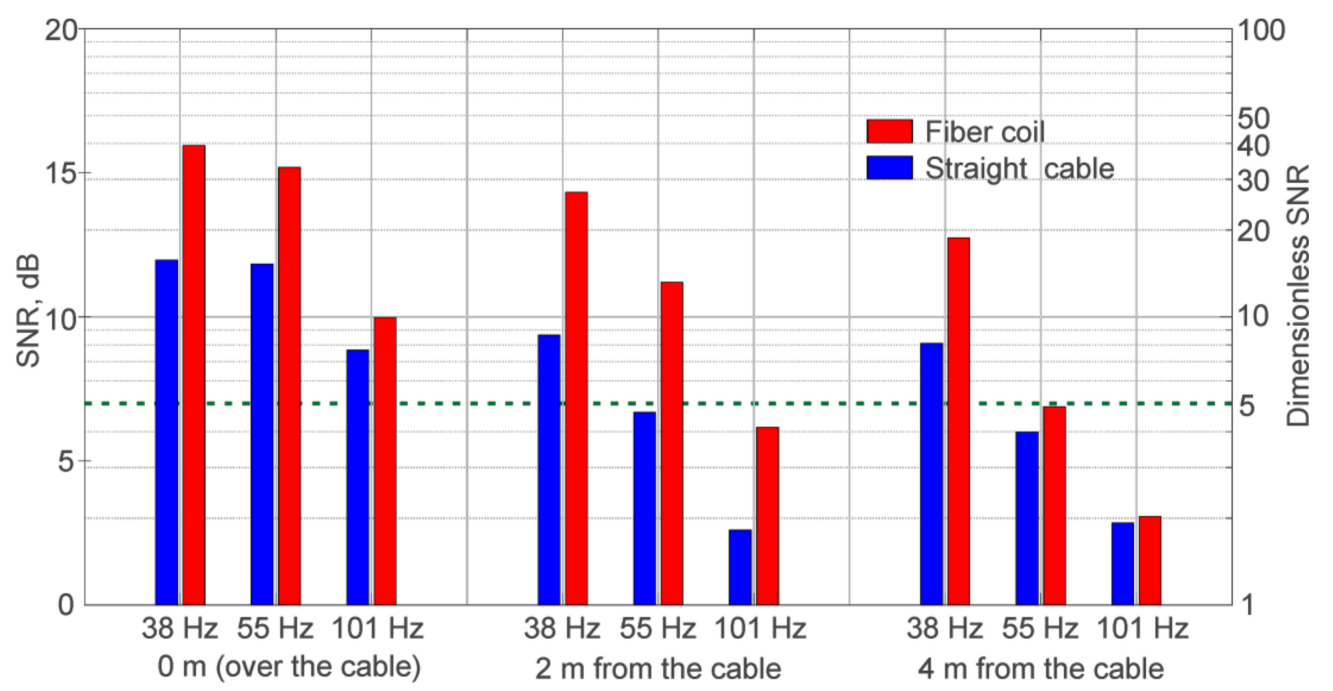

Figure 10. Plot of experimental SNR values.

As can be seen from the obtained results, the use of the fiber coil made it possible to increase the SNR by an average of 2.2 times. The obtained results were consistent with the indicators calculated in the modeling, with a difference of $12 \%$. The signal formation process in a phi-OTDR depends on many factors and its intensity has a Rayleigh distribution. As a consequence, it influences the signal intensity level and sensitivity of the device. In computer modeling, we are able to simulate a large number of realizations and obtain a histogram of possible SNR values, which is similar to the Rayleigh distribution. But it is difficult to collect the same number of data realizations in a field-test experiment since it takes significantly more time and resources. This is the reason for the deviation between SNR improvement in the simulation and in the experiments. However, even with the number of experiments performed, the values obtained are quite similar to the modeled data and allow the model estimate to be considered correct.

\section{Discussion}

The paper considered how fiber coils in cable affected the acoustic sensitivity of a phi-OTDR. To confirm the method's effectiveness, mathematical modeling was conducted for two types of systems: one with a straight cable and one with fiber coils. With a low 
impact amplitude, which a classic cable registered in less than $20 \%$ of cases, fiber coils increased the SNR by 2.5 times, which increased the detection probability to more than $95 \%$ for 1000 realizations of the simulation system. An experimental study with fiber coils, with length corresponding to the system's spatial resolution, also confirmed the method's effectiveness, and the obtained results showed that SNR increased by 2.2 times.

Author Contributions: Conceptualization, K.V.S.; methodology, K.V.S.; software, A.A.Z. and K.V.S.; validation, A.O.C. and K.I.K.; formal analysis, A.O.C. and A.A.Z.; investigation, K.V.S., R.I.K., and K.I.K.; resources, K.I.K. and R.I.K.; data curation, K.V.S. and A.A.Z.; writing-original draft preparation, K.V.S. and A.A.Z.; writing-review and editing, A.O.C. and K.I.K.; visualization, A.A.Z., and K.V.S.; supervision, A.B.P.; project administration, A.B.P. All authors have read and agreed to the published version of the manuscript.

Funding: This research was carried out within the framework of the state task.

Institutional Review Board Statement: Not applicable.

Informed Consent Statement: Not applicable.

Data Availability Statement: The data presented in this study are available on request from the corresponding author.

Conflicts of Interest: The authors declare no conflict of interest. The funders had no role in the design of the study; in the collection, analyses, or interpretation of data; in the writing of the manuscript, or in the decision to publish the results.

\section{References}

1. Baldwin, C.S. Brief history of fiber optic sensing in the oil field industry. In Proceedings of the Fiber Optic Sensors and Applications XI, Baltimore, MD, USA, 5-9 May 2014; p. 909803. [CrossRef]

2. Mateeva, A.; Lopez, J.; Potters, H.; Mestayer, J.; Cox, B.; Kiyashchenko, D.; Wills, P.; Grandi, S.; Hornman, K.; Kuvshinov, B.; et al. Distributed acoustic sensing for reservoir monitoring with vertical seismic profiling. Geophys. Prospect. 2014, 62, 679-692. [CrossRef]

3. Daley, T.M.; Freifeld, B.; Ajo-Franklin, J.; Dou, S.; Pevzner, R.; Shulakova, V.; Kashika, S.; Miller, D.; Goetz, J.; Henninges, J.; et al. Field testing of fiber-optic distributed acoustic sensing (DAS) for subsurface seismic monitoring. Lead. Edge 2013, 32, 699-706. [CrossRef]

4. Ni, J.; Wang, C.; Shang, Y.; Zhang, X.; Zhao, Y. Distributed fiber-optic acoustic sensing for petroleum geology exploration. J. Phys. Conf. Ser. 2018, 1065, 252029. [CrossRef]

5. Parker, T.; Shatalin, S.; Farhadiroushan, M. Distributed acoustic sensing-A new tool for seismic applications. First Break 2014, 32, 61-69. [CrossRef]

6. Jousset, P.; Reinsch, T.; Ryberg, T.; Blanck, H.; Clarke, A.M.; Aghayev, R.; Hersir, G.P.; Henninges, J.; Weber, M.; Krawczyk, C.M. Dynamic strain determination using fibre-optic cables allows imaging of seismological and structural features. Nat. Commun. 2018, 9, 2509. [CrossRef] [PubMed]

7. Ajo-Franklin, J.B.; Dou, S.; Lindsey, N.J.; Monga, I.; Tracy, C.; Robertson, M.; Tribaldos, V.R.; Ulrich, C.; Freifeld, B.; Daley, T.; et al. Distributed Acoustic Sensing Using Dark Fiber for Near-Surface Characterization and Broadband Seismic Event Detection. Sci. Rep. 2019, 9, 1-14. [CrossRef]

8. Kharasov, D.R.; Bengalskii, D.M.; Vyatkin, M.Y.; Nanii, O.E.; Fomiryakov, E.A.; Nikitin, S.P.; Popov, S.M.; Chamorovsky, Y.K.; Treshchikov, V.N. Extending the operation range of a phase-sensitive optical time-domain reflectometer by using fibre with chirped Bragg gratings. Quantum Electron. 2020, 50, 510. [CrossRef]

9. Shi, Y.; Wang, Y.; Zhao, L.; Fan, Z. An Event Recognition Method for $\Phi$-OTDR Sensing System Based on Deep Learning. Sensors 2019, 19, 3421. [CrossRef]

10. Wang, F.; Liu, Z.; Zhou, X.; Li, S.; Yuan, X.; Zhang, Y.; Shao, L.; Zhang, X. Oil and gas pipeline leakage recognition based on distributed vibration and temperature information fusion. Results Opt. 2021, 5, 100131. [CrossRef]

11. Papp, A.; Wiesmeyr, C.; Litzenberger, M.; Garn, H.; Kropatsch, W. Train Detection and Tracking in Optical Time Domain Reflectometry (OTDR) Signals. In Proceedings of the German Conference on Pattern Recognition, Hannover, Germany, 12-15 September 2016; pp. 320-331.

12. Peng, F.; Duan, N.; Rao, Y.; Li, J. Real-Time Position and Speed Monitoring of Trains Using Phase-Sensitive OTDR. IEEE Photonics J. 2014, 26, 2055-2057. [CrossRef]

13. Taylor, H.F.; Lee, C.E. Apparatus and Method for Fiber Optic Intrusion Sensing. U.S. Patent 5194847 A, 16 March 1993.

14. Juarez, J.C.; Maier, E.W.; Choi, K.N.; Taylor, H.F. Distributed Fiber-Optic Intrusion Sensor System. J. Lightwave Technol. 2005, 23, 2081. [CrossRef] 
15. Juarez, J.C.; Taylor, H.F. Field test of a distributed fiber-optic intrusion sensor system for long perimeters. Appl. Opt. 2007, 46, 1968-1971. [CrossRef] [PubMed]

16. Aktas, M.; Akgun, T.; Demircin, M.U.; Buyukaydin, D. Deep learning based multi-threat classification for phase-OTDR fiber optic distributed acoustic sensing applications. SPIE Commer. Sci. Sens. Imaging 2017, 10208, 102080. [CrossRef]

17. Shiloh, L.; Eyal, A.; Giryes, R. Deep learning approach for processing fiber-optic DAS seismic data. In Proceedings of the 26th International Conference on Optical Fiber Sensors (Optical Society of America, Lausanne, Switzerland, 24-28 September 2018. [CrossRef]

18. Wang, Z.; Zeng, J.; Li, J.; Fan, M.; Wu, H.; Peng, F.; Zhang, L.; Zhou, Y.; Rao, Y. Ultra-long phase-sensitive OTDR with hybrid distributed amplification. Opt. Lett. 2014, 39, 5866-5869. [CrossRef] [PubMed]

19. Wang, Z.; Zeng, J.; Li, J.; Peng, F.; Zhang, L.; Zhou, Y.; Wu, H.; Rao, Y. 175 km Phase-sensitive OTDR with Hybrid Distributed Amplification. Proc. SPIE 2014, 9157, 9157D5. [CrossRef]

20. Tian, X.; Yu, Y.; Zhao, M.; Jiang, G. Long distance $\Phi$-OTDR system based on Raman and EDFA synthetic amplification. In AOPC 2017: Fiber Optic Sensing and Optical Communications; International Society for Optics and Photonics: Bellingham, WA, USA, 2017; Volume 10464. [CrossRef]

21. Lu, B.; Zheng, H.; Wang, Z.; Ye, Q.; Wei, F.; Qu, R.; Cai, H. High spatial resolution $\Phi$-OTDR with long sensing distance. In Optical Fiber Sensors; Optical Society of America: Washington, DC, USA, 2018; p. ThE25. [CrossRef]

22. Stepanov, K.V.; Zhirnov, A.A.; Chernutsky, A.O.; Choban, T.V.; Pnev, A.B.; Lopunov, A.I.; Butov, O.V. Spatial Resolution Improvement for phi-OTDR Sensors via Weak Fiber Bragg Gratings. In Proceedings of the 2020 International Conference Laser Optics (ICLO), St. Petersburg, Russia, 2-6 November 2020. [CrossRef]

23. Marcon, L.; Soto, M.A.; Soriano-Amat, M.; Costa, L.; Fernandez-Ruiz, M.R.; Martins, H.F.; Palmieri, L.; Gonzalez-Herraez, M High-Resolution Chirped-Pulse $\phi$-OTDR by Means of Sub-Bands Processing. J. Light. Technol. 2020, 38, 4142-4149. [CrossRef]

24. Hofmann, J.; Facchini, M.; Lowell, M. Analysis of the acoustic response in water and sand of different fiber optic sensing cables. In Sensors for Extreme Harsh Environments II; International Society for Optics and Photonics: Bellingham, WA, USA, 2015; Volume 9491, p. 94910E. [CrossRef]

25. Freeland, R.S.; Chow, B.; Williams, J.; Godfrey, A. Relative acoustic sensitivity of standard telecom and specialty optical fiber cables for distributed sensing. In Fiber Optic Sensors and Applications XIV; International Society for Optics and Photonics: Bellingham, WA, USA, 2017; Volume 10208. [CrossRef]

26. Han, B.; Guan, H.; Yao, J.; Rao, Y.J.; Ran, Z.; Gong, Y.; Li, Q.; Li, M.; Zhang, R.; An, S.; et al. Distributed acoustic sensing with sensitivity-enhanced optical cable. IEEE Sens. J. 2020, 21, 4644-4651. [CrossRef]

27. Goldner, E.L.; Andersen, J.K.; Cherbettchian, A.H. Fiber optic acoustic sensor arrays and systems, and methods of fabricating the same. U.S. Patent No. 9217801, 22 December 2015.

28. Martin, J.; Donno, D.; Papp, B.; Hartog, A. Fiber optic distributed vibration sensing with directional sensitivity. U.S. Patent No. 9880047, 30 January 2018.

29. He, H.; Shao, L.; Li, H.; Pan, W.; Luo, B.; Zou, X.; Yan, L. SNR enhancement in phase-sensitive OTDR with adaptive 2D bilateral filtering algorithm. IEEE Photonics J. 2017, 9, 6802610. [CrossRef]

30. Sun, Q.; Feng, H.; Yan, X.; Zeng, Z. Recognition of a Phase-Sensitivity OTDR Sensing System Based on Morphologic Feature Extraction. Sensors 2015, 15, 15179-15197. [CrossRef] [PubMed]

31. Stepanov, K.V.; Zhirnov, A.A.; Chernutsky, A.O.; Koshelev, K.I.; Pnev, A.B.; Lopunov, A.I.; Butov, O.V. The Sensitivity Improvement Characterization of Distributed Strain Sensors Due to Weak Fiber Bragg Gratings. Sensors 2020, 20, 6431. [CrossRef] [PubMed]

32. Yatseev, V.A.; Zotov, A.M.; Butov, O.V. Combined Frequency and Phase domain time-gated reflectometry based on a fiber with reflection points for absolute measurements. Results Phys. 2020, 19, 103485. [CrossRef]

33. de Miguel Soto, V.; Jason, J.; Kurtoğlu, D.; Lopez-Amo, M.; Wuilpart, M. Spectral shadowing suppression technique in phaseOTDR sensing based on weak fiber Bragg grating array. Opt. Lett. 2019, 44, 526-529. [CrossRef]

34. Zhu, F.; Zhang, Y.; Xia, L.; Wu, X.; Zhang, X. Improved $\Phi$-otdr sensing system for high-precision dynamic strain measurement based on ultra-weak fiber Bragg grating array. J. Lightwave Technol. 2015, 33, 4775-4780. [CrossRef]

35. Liu, T.; Wang, F.; Yuan, Q.; Liu, Y.; Zhang, L.; Zhang, X. Simulation of the performance of phase-sensitive OTDR based on ultra-weak FBG array using double pulses. In Proceedings of the 2017 16th International Conference on Optical Communications and Networks (ICOCN), Wuzhen, China, 7-10 August 2017; pp. 1-3. [CrossRef]

36. Liu, T.; Wang, F.; Zhang, X.; Zhang, L.; Yuan, Q.; Liu, Y.; Yan, Z. Phase sensitive distributed vibration sensing based on ultraweak fiber Bragg grating array using double-pulse. Opt. Eng. 2017, 56, 084104. [CrossRef]

37. Wang, F.; Liu, T.; Yuan, Q.; Liu, Y.; Niu, J.; Zhang, X.; Zhang, L. High performance interrogation of ultra-weak FBG array using double-pulse and heterodyne coherent detection. In Conference on Lasers and Electro-Optics/Pacific Rim; Optical Society of America: Washington, DC, USA, 2017; p. 1119. [CrossRef]

38. Liu, T.; Wang, F.; Zhang, X.; Yuan, Q.; Niu, J.; Zhang, L.; Wei, T. Interrogation of ultra-weak FBG array using double-pulse and heterodyne detection. IEEE Photonics Technol. Lett. 2018, 30, 677-680. [CrossRef]

39. Liu, Y.; Wang, F.; Zhang, X.; Zhang, Y.; Xu, W.; Zhang, L. High performance interrogation by a composite-double-probe-pulse for ultra-weak FBG array. In 17th International Conference on Optical Communications and Networks (ICOCN2018); International Society for Optics and Photonics: Bellingham, WA, USA, 2019; Volume 11048, p. 110483U. [CrossRef] 
40. Wang, F.; Liu, Y.; Wei, T.; Zhang, Y.; Ji, W.; Zong, M.; Zhang, X. Polarization fading elimination for ultra-weak FBG array-based S-OTDR using a composite double probe pulse approach. Opt. Express 2019, 27, 20468-20478. [CrossRef]

41. Zhirnov, A.A.; Stepanov, K.V.; Chernutsky, A.O.; Fedorov, A.K.; Nesterov, E.T.; Svelto, C.; Pnev, A.B.; Karasik, V.E. Influence of the Laser Frequency Drift in Phase-Sensitive Optical Time Domain Reflectometry. Opt. Spectrosc. 2019, 127, 656-663. [CrossRef]

42. Taherzadeh, S.; Attenborough, K. Deduction of ground impedance from measurements of excess attenuation spectra. J. Acoust. Soc. Am. 1999, 105, 2039-2042. [CrossRef] 